\title{
Samuel Beckett et l'écriture des ruines de Mercier et Camier à Soubresauts
}

\author{
Llewellyn Brown (2020). \\ París: Classiques Garnier-Lettres Modernes Minard.
}

\section{0}

Lucas Margarit

Universidad de Buenos Aires, Argentina

Llewellyn Brown presenta una línea de investigación sobre la obra de Samuel Beckett donde la perspectiva filosófica y el psicoanálisis se funden en una serie de nuevas aproximaciones a la obra del autor irlandés. Entre sus obras quisiera destacar Beckett, les fictions brèves: voir et dire (2008), Beckett, Lacan and the Voice (2016) y Beckett, Lacan and the Gaze (2019), asimismo dirige la serie "Samuel Beckett" en La Revue des Lettres modernes de ediciones Minard.

En esta ocasión comentaremos un libro que apareció el año pasado y se centra en la presencia de las ruinas en la obra de Beckett partiendo de un texto muy temprano y que ya anuncia desde el título el motivo que será el eje de este libro de Brown. Se trata del texto radiofónico "The Capital of the Ruins" (1946) donde el autor hace alusión a su experiencia de la guerra cuando formaba parte de la Cruz Roja en la ciudad de Saint-Lô, destruida por bombardeos continuos. Recordemos que Beckett ha escrito un breve poema con el nombre de esta ciudad. Volviendo al libro, Llewellyn Brown hace un rastreo del término "ruine" y establece un recorrido cultural que parte desde las Arcadias donde las ruinas implican un prestigio que perdura hasta la Segunda Guerra Mundial con la experiencia que recién comentamos de Beckett, desde las referencias a vestigio en la obra de Chateaubriand en Génie du Christianisme hasta las últimas obras de nuestro autor. Es un recorrido extenso que nos permite ver de qué modo este tópico se fue desarrollando en una poética particular y también da cuenta de los diálogos que se exponen entre las diferentes obras tratadas, ya sea teóricas como críticas y literarias propiamente dichas.

El volumen comienza con una "Introduction" donde ya esboza los lineamientos teóricos en los que se va a centrar esta investigación. Nos propone una serie de lecturas que va articulando de manera clara de qué modo se fue conformando en la historia la idea de "poética de las ruinas" a partir del texto ya clásico para este tema de Diderot, Salon 1767, donde alude sobre todo a las obras de Hubert Robert (p.16). Asimismo, interpela las posturas del Romanticismo hasta los libros de W.G. Sebald o Jean Starobinski. Es claro el recorrido que nos propone para volver a pensar la relación entre ruina y obra literaria y de qué modo esta idea de ruina no describe sólo la temática de ciertos textos, sino también la naturaleza de ese lenguaje que da cuenta de su propia ruindad.

Uno de los puntos que propone es la consideración de ruina como ley de la existencia humana, incluso como "expresión de la ausencia de toda metafísica o de visión del mundo" (p.24). Sin duda es una afirmación que abre una serie de debates pero que enfoca su análisis en el aspecto material del mundo que es el que también se presenta en la obra beckettiana.

Es entonces que Brown comenzará a pensar la "cualidad arquitectónica” de los textos de Beckett, lo cual será el motivo central del siguiente capítulo. El espacio por donde se mueve el cuerpo establece un patrón de degradación que expone un "imaginario especular que toma la forma de un campo de ruinas" (p.35) para proyectarse en esos cuerpos que han perdido su imagen total y totalizadora y deben conformarse sólo con vestigios que es lo único a lo que podríamos acceder. En el capítulo titulado “L'Humanité en ruines" retoma las referencias al texto radiofónico y al poema "Saint-Lô" a los que ya hicimos referencia, donde se pasa de una perspectiva más objetivada a un poema de carácter más subjetivo. En este capítulo, además, establece una relación entre ruina, Historia y Humanidad que es muy atinada para considerar una poética del desastre o del fracaso tal como se ha pensado la obra del autor de Waiting for Godot.

En estos territorios y paisajes, ante estos cuerpos enfermos, estos personajes también se enfrentan a la expulsión de un refugio (imaginario o no) que también los expone a un paisaje desolado: ya sea un 
espacio abierto a una naturaleza agonizante o a un confinamiento desde donde se observa un entorno en ruinas.

La siguiente sección titulada "Expulsion et quête d'un refuge" se focaliza en la situación en la que se encuentran muchos de sus personajes. Una expulsión que nos permite pensar en la relación de la obra de Beckett con Dante y los condenados en la Commedia así como también en una serie de recorridos exasperados por encontrar un espacio donde reposar. El libro que estamos comentando nos conduce por un catálogo de situaciones que le permite al autor reflexionar sobre gran cantidad de procesos a los que se enfrentan estos personajes, desde la enfermedad psíquica hasta la física; desde la huida hasta los "faux refuges", por ejemplo en Film. A partir de estas posibilidades Brown explaya una serie de contactos entre la obra de Beckett y el psicoanálisis, especialmente con la obra de Jacques Lacan. Es este uno de los puntos destacables de este trabajo, el modo como va constituyendo entramados entre la obra y diferentes disciplinas que el autor se permite utilizar para encausar su posición ante la obra beckettiana. De analizar en algunas obras como Molloy un deambular sin rumbo, la imagen topográfica o el paisaje por donde circulan los personajes, Brown pasa a considerar la serie de lugares cerrados que se repiten en varias de las obras de Beckett. Lo interesante es que no se detiene en la descripción, sino que ofrece -a veces- más que una reflexión una relación entre obras y tópicos que nos permiten establecer nuevas relaciones entre ellas a partir del nodo de análisis que nos propone. El tema de las ruinas es abordado desde lo literal hasta lo metafórico, desde lo arquitectónico hasta lo corporal o psíquico. Uno de los puntos centrales de la poética de Beckett con respecto al encierro es el de la realidad mental encerrada en el cráneo, al cual este estudio le dedica un apartado en esta sección recorriendo varias obras en prosa, sobre todo de sus obras breves.

"Briser la clôture" es el título del siguiente capítulo que comienza con el apartado "L'absence d'espoir". En esta sección continúa con los motivos que ya viene desarrollando, las lecturas de Leopardi, Dante o Chmafort y también refiriéndose a narraciones como L'Expulsé u obras breves como Nacht und
Träume. Los siguientes apartados están reunidos bajo el título "Motifs de Subjectivité dans "Pour finir encore" et "Sans"”. En dos secciones posteriores, Browne aborda un análisis pormenorizado de estas obras. La primera a partir de sus elementos de composición donde se detiene en los modos y usos particulares de la palabra y qué función cumple en la constitución de esta prosa breve (detenerse en la descripción, acelerar, el problema de la puntuación), luego la espacialidad, la relación entre experiencia o empiria y pensamiento. La reflexión sobre el segundo ejemplo, "Sans" nos conduce de la cuestión más tematizada de la ruina tal como se lo podría considerar con respecto a "Pour finir encore" a pensar la escritura misma como la representación de una ruina donde la sintaxis parece diluirse en pos de una experiencia de la fragmentación y el deterioro. Brown nos conduce por una minuciosa reflexión acerca de un problema muy cercano a la poética de Beckett, reconoce el modo cómo se desarrolla este tópico desde los textos iniciales hasta los de su última etapa ya sea como dramaturgo o como prosista. Sin dudas el autor conoce de manera muy precisa la obra de Beckett y sus acercamientos, novedosos, son un incentivo para comenzar a leer la obra de Beckett desde nuevas perspectivas. Por otra parte, cubre una gran zona de la producción de nuestro autor, incluso de correspondencia que ilumina algunas de las afirmaciones de Brown. Cabe destacar también el modo claro en que establece relaciones entre obras e ideas sin caer en repeticiones estériles ni en obviedades. Por momentos las repeticiones son utilizadas para enfatizar una idea, pero también para girar el objeto de análisis y observarlo con una nueva mirada. Nos pareció muy interesante el apartado de los "falsos refugios" donde recupera el recorrido de la huida y aquellos apartados dedicados a la experiencia íntima y mental de los personajes que se centran en la imagen del "cráneo" como parte de una iconografía de la experiencia de un sujeto siempre ensimismado.

Browne de este modo nos acerca un libro ameno sin dejar de ser reflexivo y profundo, abarcativo con respecto a la obra de Beckett, a las lecturas que nos propone atravesando los hipotextos y a los acercamientos teóricos sólidos que presenta y presupone su lectura. 